\title{
La nueva filosofía de la naturaleza del hombre de Oliva Sabuco
}

\author{
Mònica Balltondre \\ Universitat Autònoma de Barcelona \\ monica.balltondre@uab.es
}

\begin{abstract}
En este número estamos ante una clásica transexual por intervención historiográfica. En 1587 a nombre de Oliva Sabuco vieron la luz nueve coloquios, bajo un solo libro, con el título de "Nueva filosofía de la naturaleza del hombre no conocida ni alcanzada de los grandes filósofos antiguos: la cual mejora la vida y salud humana", con una reimpresión al año siguiente. Siguió siendo Oliva Sabuco de Nantes Barrera en la historia hasta entrado el siglo XX, cuando la publicación de dos documentos dieron al traste con la imagen que se tenía de una joven escritora renacentista. En 1903, José Marco Hidalgo, registrador de la propiedad en Alcaraz, lugar natal de los Sabuco, y eventual historiador, hizo público un testamento y una escritura de poder donde el padre de la escritora reclamaba la autoría de la nueva filosofía. En el testamento ${ }^{1}$, Miguel Sabuco afirmaba que había puesto a su hija de autora "solo por darle el nombre e la onrra" (Marco, 1903, p. 8), sin decirnos por qué se arrepintió, en el último momento, de ese previo acto de generosidad paterno filial que supuestamente había tenido. Y aunque están los prólogos y la petición de amparo y favor real para imprimir la obra bajo la rúbrica de una mujer, y el subsiguiente privilegio real concedido también a su nombre, la historiografía posterior no ha dudado en transformar a Oliva en Miguel ${ }^{2}$. Pocos datos tenemos, por el momento, de la familia Sabuco, por ejemplo, acerca de la formación intelectual de ambos, pero no parece descabellado mantener la duda de la autoría, pues se pueden dar argumentos para sostener ambas posibilidades, e incluso pensar en una labor a cuatro manos.
\end{abstract}

Evitando caer en la tentación de sobreinterpretar los escasos datos biográficos disponibles, sí que me atrevo, quizá imprudentemente, a esgrimir un argumento de tipo textual en favor de la hija. En el primer coloquio me parece haber encontrado muchas más referencias al sexo femenino de las que cabría esperar en un texto de la época. Si la comparamos con otras obras coetáneas, e incluso con libros dirigidos a mujeres, como: Los coloquios matrimoniales de Pedro Luján (1550), donde las interlocutoras son mujeres, hablando de temas de mujeres, creemos notar en el primer coloquio de la obra de Sabuco una consideración atenta hacia la mujer, que no pasa por un aprecio superior a la condición femenina, sino por un especial cuidado por considerarla. Si bien frases del tipo: "este afecto obra más en las mujeres" (Sabuco, 1588, fol. 11), "éste obra mucho en las mujeres, y más en las preñadas" (Sabuco, 1588, fols. 14; 22) podían ser más o menos típicas en los escritos de avisos para la salud, el hecho que, hablando del hombre en genérico, tome en cuenta a la mujer, parece bastante atípico por aquel entonces: "así el hombre y la mujer, con todo el saber" (Sabuco, 1588, fol. 16), "que

${ }^{1}$ El testamento puede leerse en red: www.sabuco.org.

${ }^{2}$ A excepción reciente de varias historiadoras y filólogas que, desde diferentes frentes, están intentando devolver la autoría a la hija. 
de cien hombres o cien mujeres, mueren los ochenta de enojo y pesar" (Sabuco, 1588, fol. 15), "para no darle crédito al hombre o mujer que la tuviere"(Sabuco, 1588, fol. 23), "y todo el mundo sabe que muchos y muchas murieron de amores, y otros y otras muchas se mataron" (Sabuco, 1588, fol. 26). Estas muestras sólo las encontramos en el primer coloquio ${ }^{3}$ : Coloquio del conocimiento de sí, del que editamos aquí una parte. El primer coloquio trae avisos para ambos sexos y su propuesta médica va dirigida a toda la humanidad, y no es que quiera trasmitir conocimiento ni comprensión de la condición femenina en especial. Por eso mismo, es insólito que aluda al género femenino con tanta frecuencia y específicamente. Puede que este argumento no sea muy sólido, pero en todo caso, nos resistimos a dar por zanjada la cuestión de la autoría y preferimos mantener a la hija, porque al fin y al cabo, es a ella a quien se le concedió el privilegio real de publicación en su momento.

Antes de dar paso a su voz, demos algunas claves interpretativas para poder gozar mejor de sus palabras. Sabuco en su obra intenta dar respuesta a las muertes violentas, aquellas que llegan antes del curso natural de la vida de una/o. En esa hora histórica, era habitual que la filosofía se inmiscuyera en la medicina y viceversa. Así que no nos debemos dejar engañar por el título de la obra, porque lo que nos propone Oliva Sabuco en ella es fundamentalmente una renovación del saber médico de la época, dominado por el galenismo. El primer coloquio viene a ser una primera enunciación de sus ideas filosófico-médicas (y por ello lo he escogido como muestra), que después sustentará fisiológicamente en el Coloquio de la Vera Medicina, presentando una fisiología de preeminencia cerebral, basada en la imagen del hombre como árbol del revés, cuya raíz y principio de funcionamiento y mantenimiento es el cerebro.

Oliva Sabuco hilvanará su primer coloquio de la mano del manido precepto helénico latinizado nosce te ipsum. Conocerse a una/o misma/o supone, ante todo, conocer la naturaleza del alma, con un doble fin que se identifica en nuestra autora, estar sana/o y ser feliz. Para ella, conocerse es conocer los males anímicos que nos acechan y Antonio, alter ego libresco de Sabuco, defenderá la importancia que los afectos tienen para la salud. La tesis central de la autora es que las pasiones nos pueden matar o dejarnos mal humor de enfermedad en el cuerpo. Según ella, inspirada en buena medida en el Timeo de Platón, las pasiones desmesuradas desbaratan la armonía entre el cuerpo y el alma, armonía principal para la salud, que se da en el cerebro ${ }^{4}$. Su argumento es que el alma, cuando recibe impresiones aborrecibles, las quiere expulsar, y con ello provoca una caída de cierto flujo cerebral, que según su cantidad, calidad (depende de cómo se vicie) y/o lugar a donde vaya a parar, supondrá un tipo de enfermedad u otro.

Dentro de la antropología cristiana del siglo XVI, la composición natural del hombre, ordenada por Dios, sigue siendo la de estar formados por dos partes claramente distinguibles, pero a la vez, necesarias e inseparables para ser personas, que son el cuerpo y el alma. Las pasiones formaban parte de la dinámica anímica, externas al cuerpo como realidad asomática, pero dentro de la persona y, por lo tanto, naturales a ella. Dios las había dado al hombre y a los animales como impulsos que ayudaban a la conservación de sus naturalezas. Estaban para espolear al ser a perseguir aquello saludable y a apartarse de lo nocivo. Así, se creía que de nuestra parte de alma sensitiva nos nacían

${ }^{3}$ Aunque la coherencia temática y en buena medida formal con los restantes coloquios hace sospesar su participación en ellos también.

${ }^{4}$ Incluso la distribución del jugo que alimenta el cuerpo la hace depender nuestra autora de éste órgano, cuando lo habitual dentro de la medicina galénica era que se encargara de ello el hígado. 
estas inclinaciones, que son el gozo, el deseo, la esperanza, el amor, la alegría, el dolor, el miedo, la vergüenza o la ira, por ejemplo. Estos apetitos se entendían como perturbaciones, movimientos inherentes al alma, afectando al cuerpo desde el corazón, que perseguían o eran desencadenados por algo exterior. En tanto que naturales, las pasiones funcionaban de un modo necesario en los animales, pero en el hombre, por tener éste una parte superior, el alma racional, ligada a la voluntad y al libre albedrío, que escapaba a lo dado conforme natura, estos apetitos se le podían convertir en vicios (la lujuria, la gula, etc.). Por ello, fue tópica durante muchos siglos tratar los males que las pasiones nos acarreaban como humanos, pues estos autores creían que las pasiones humanas a menudo se dejaban engañar por la imaginación, la fantasía o por juicios erróneos, y nos arrastraban a perseguir lo que nuestra fantasía creía bueno, y no lo que nuestro entendimiento debía juzgar rectamente.

Sabuco, por boca de Antonio, disertará sobre los dos tipos de vida anímica que cree que más nos enferman: los afectos negativos y/o desmesurados, y los vicios de la racional (los pecados). Y su terapia va a residir primero en hacernos ver cómo estos afectos nos afectan. El primer paso para vencer a "estas armas de la muerte" como ella las llama, es ser conscientes de su poder para enfermarnos físicamente, para lo cual desplegará multitud de ejemplos, casos que funcionan como demostración, a la par que aviso moral y fuerza terapéutica, al estilo de Cicerón y Séneca. $Y$ en segundo lugar, debemos aprender a darnos buenas razones para dominarlas. De modo que, el instrumento por excelencia que nos va a ofrecer para la curación de los desórdenes anímicos son las palabras. Palabras que deben llegar a nuestros entendimientos y persuadir/mover nuestra voluntad a desear aquello que es correcto (dentro del dogma cristiano) que siempre será saludable, a sus ojos.

A continuación, de la obra de Sabuco, ofrecemos la primera carta al lector y la carta dedicatoria al rey, seguido de algunas partes del primer coloquio. En lo que atañe a la edición de estas partes, se ha intentado respetar la forma y sentido original del texto, buscando los equivalentes actuales para las grafías y la puntuación ${ }^{5}$. De este modo, se ha acentuado y se han modernizado la grafías según la norma actual: "ss" por "s", "u" por "v/b", "x" por "j", "i" por "y", etc., sin modificar los consonantismos propios de la época: "preceto", "invidia" o "celebro", por ejemplo, y manteniendo también las contracciones genuinas: dél, dellas, destas, etc. La puntuación responde casi por entero a nuestra mano.

\section{Referencias}

Luján, Pedro (1550). Los coloquios matrimoniales. Edición a cargo de Asunción Rallo. Madrid: Real Academia Española, 1990.

Marco Hidalgo, José (1903). Doña Oliva de Sabuco no fue escritora. Revista de archivos, bibliotecas y museos. Año VII. Tomo 9, 3ª́poca. 1, 1-13.

\footnotetext{
${ }^{5}$ La falta de una buena edición actual hace que esta tarea haya que tenido que correr a mi cargo, pero no hubiera sido posible sin la colaboración de Kitina Maestres y el asesoramiento lingüístico de Xavier Tubau, con los cuales quedo en deuda.
} 
Sabuco de Nantes y Barrera, Oliva (1587). Nueva filosofía de la naturaleza del hombre, no conocida ni alcançada de los grandes filosofos antiguos: la qual mejora la vida y salud humana. En Madrid, por P. Madrigal.

Sabuco de Nantes y Barrera, Oliva (1588): Nueva filosofía de la naturaleza del hôbre, no conocida ni alcançada de los grandes filosofos antiguos: la qual mejora la vida y salud humana. En Madrid, por P. Madrigal.

\section{Formato de citación}

Balltondre, Mònica. (2006). La nueva filosofía de la naturaleza del hombre de Oliva Sabuco. Athenea Digital, 10, 259-262. Disponible en http://antalya.uab.es/athenea/num10/sabuco.pdf.

Este texto está protegido por una licencia Creative Commons.
Usted es libre de copiar, distribuir y comunicar públicamente la obra bajo las
siguientes condiciones:
Reconocimiento: Debe reconocer y citar al autor original.
No comercial. No puede utilizar esta obra para fines comerciales.
Sin obras derivadas. No se puede alterar, transformar, o generar una obra
derivada a partir de esta obra.
$\underline{\text { Resumen de licencia }}$
Texto completo de la licencia




\title{
Nueva filosofía de la naturaleza del
}

\section{hombre no conocida ni alcanzada de los}

grandes filósofos antiguos: la cual

mejora la vida y salud humana

\author{
Oliva Sabuco de Nantes
}

\begin{abstract}
Al lector.
Cosa injusta es y contra razón (prudente lector) juzgar de una obra sin verla ni entenderla. Equidad y justicia hacía aquel filósofo, que cuando oía alguna diferencia atapábala una oreja y la guardaba para oír la otra parte. Pues esta es la merced que aquí te pido, que no juzgues deste libro hasta que hayas visto y entendido su justicia, pasándolo y percibiéndolo todo. Entonces pido tu parecer y no antes. $Y$ suplico a los sabios médicos, esperen con prudencia al tiempo, experiencia y suceso que declaran a vistas de ojos la verdad. Bien conozco que por haberse dejado los antiguos intacta y olvidada esta filosofía, y por haberse quedado la verdad tan atrás mano, parece ahora novedad o desatino, siendo como es la verdadera, mejor y de más fruto para el hombre. Pero si consideras lo poco que el entendimiento humano sabe, en comparación de lo mucho que ignora, y que el tiempo, inventor de las cosas, va descubriendo cada día más en todas las artes y en todo género de saber, no darás lugar (benigno lector) a que la injusta invidia, emulación o interese prive al mundo de poderse mejorar en el saber que más importa y más utilidad y fruto puede dar al hombre. Vale.
\end{abstract}

\section{Carta dedicatoria, al Rey nuestro señor.}

Una humilde sierva y vasalla, hincadas las rodillas en ausencia pues no puede en presencia, osa hablar. Diome esta osadía y atrevimiento aquella ley antigua de alta caballería, a la cual los grandes señores y caballeros de alta prosapia, de su libre y espontánea voluntad se quisieron atar y obligar, que fue favorecer siempre a las mujeres en sus aventuras. Diome también atrevimiento aquella ley natural de la generosa magnanimidad que siempre favorece a los flacos y humildes, como destruye a los soberbios. La magnanimidad natural y no aprendida del león (rey y señor de los animales) usa de clemencia con los niños y con las flacas mujeres, especial si postrada por tierra tiene osadía y esfuerzo para hablar, como tuvo aquella cautiva de Getulia huyendo del cautiverio por una montaña, donde había muchos leones, los cuales todos usaron con ella de clemencia y favor, por ser mujer y por aquellas palabras que osó decir con gran humildad. Pues así yo con este atrevimiento y osadía, oso ofrecer y dedicar este mi libro a. V.C.M. y pedir el favor del gran león, rey y señor de los hombres, y pedir amparo y sombra de las Aquilinas a las de V.C.M. debajo de las cuales pongo este mi hijo que yo he engendrado. $Y$ reciba V.M. este servicio de una mujer, que pienso es mayor en calidad que cuantos han hecho los hombres, vasallos o señores, que han deseado servir a V.M. Y aunque la cesárea y católica Majestad tenga dedicados muchos libros de hombres, a lo menos de mujeres pocos y raros, y ninguno desta materia. Tan extraño y nuevo es el libro, cuanto es el autor. Trata del 
conocimiento de sí mismo, y da dotrina para conocerse y entenderse el hombre a sí mismo y a su naturaleza. $Y$ para saber las causas naturales por que vive y por que muere o enferma. Tiene muchos y grandes avisos para librarse de la muerte violenta. Mejora el mundo en muchas cosas. A las cuales si V.M. no puede dar orden, ocupado en otros negocios, por ventura los venideros lo harán, de todo lo cual se siguen grandes bienes. Este libro faltaba en el mundo, así como otros muchos sobran. Todo este libro faltó a Galeno, a Platón y a Hipócrates en sus tratados De natura humana; y a Aristóteles cuando trató De anima y De vita et morte. Faltó también a los naturales como Plinio, Eliano y los demás cuando trataron De homine. Ésta era la filosofía necesaria y la mejor y de más fruto para el hombre, y ésta toda dejaron intacta los grandes filósofos antiguos. Ésta compete especialmente a los reyes y grandes señores, porque en su salud, voluntad y conceptos, afectos y mudanzas, va más que en las de todos. Ésta compete a los reyes, porque conociendo y entendiendo la naturaleza y propiedades de los hombres, sabrá mejor regirlos y gobernar su mundo, así como el buen pastor rige y gobierna mejor su ganado cuando le conoce su naturaleza y propiedades. Deste coloquio del conocimiento de sí mismo y naturaleza del hombre, resultó el diálogo de la Vera medicina que allí se vio nacida, no acordándome yo de medicina porque nunca la estudié, pero resulta muy clara y evidentemente, como resulta la luz del sol, estar errada la medicina antigua que se lee y estudia en sus fundamentos principales, por no haber entendido ni alcanzado los filósofos antiguos y médicos su naturaleza propia, donde se funda y tiene su origen la Medicina. De lo cual, no solamente los sabios y cristianos médicos pueden ser jueces, pero aún también los de alto juicio de otras facultades y cualquier hombre hábil y de buen juicio, leyendo y pasando todo el libro. De lo cual, no solamente sacará grandes bienes en conocerse a sí mismo y entender su naturaleza, afectos y mudanzas, y saber por qué vive o por qué muere o enferma, y otros grandes avisos para evitar la muerte violenta, y cómo podrá vivir felice en este mundo, pero aun también entenderá la medicina clara, cierta y verdadera, y no andará a ciegas con ojos y pies ajenos ni será curado del médico como el jumento del albéitar, que ni ve ni oye ni entiende lo que le curan, ni sabe por qué ni para qué. Pero especialmente los médicos de buen juicio, cristianos, libres de interese y magnánimos, que estimen más el bien público que el suyo particular, luego verán de lejos relucir las verdades desta filosofía, como relucen en las tinieblas los animalejos lucientes en la tierra y las estrellas en el cielo. Y el que no la entendiere ni comprendiera déjela para los otros y para los venideros, o crea a la experiencia, y no a ella, pues mi petición es justa, que se pruebe esta mi secta un año, pues han probado la medicina de Hipócrates y Galeno dos mil años y en ella han hallado tan poco efeto y fines tan inciertos, como se ve claro cada día y se vido en el gran catarro, tabardete, viruelas y en pestes pasadas, y otras muchas enfermedades, donde no tiene efeto alguno, pues de mil no viven tres todo el curso de la vida hasta la muerte natural, y todos los demás mueren muerte violenta de enfermedad sin aprovechar nada su medicina antigua. Y si alguno por haber yo dado avisos de algunos puntos desta materia en tiempo pasado, ha escrito o escribe, usurpando estas verdades de mi invención, suplico a V.C.M. mande las deje, porque no mueva a risa como la corneja vestida de plumas ajenas. Y no se contente V.M. con oírlo una vez, sino dos y tres, que cierto él dará contento y alegría y gran premio y fruto. Tuve por bien de no enfadar con la ostentación de muchas alegaciones ni refutaciones, porque estas impiden el entendimiento y estorban el gusto por la materia que se va hablando. Cuan extraño, más alto, mejor y de más fruto es este libro que otros muchos, tan extrañas, mejores y extraordinarias mercedes espera esta humilde sierva de V. M., cuyas reales manos besa y en todo próspero suceso salud, gracia, y eterna gloria le desea.

Catholicae tua Maiestatis Ancilla,

Oliva Sabuco de Nantes Barrera 


\title{
COLOQUIO DEL CONOCIMIENTO DE SÍ MISMO, EN EL CUAL HABLAN TRES PASTORES FILÓSOFOS EN VIDA SOLITARIA, NOMBRADOS ANTONIO, VERONIO, RODONIO.
}

\author{
Título primero. De la plática de los pastores en que mueven la materia y proponen sus \\ preguntas.
}

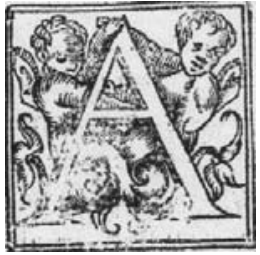

NTONIO. Qué lugar este tan alegre, apacible y grato para la dulce conversación de las Musas. Asentémonos y aflojemos las venas del cuidado, pues este alegre ruido del agua, el dulce murmurar de los árboles al viento, el suave olor destos rosales y prado nos convidan a filosofar un rato.

VERONIO. ¿Quién es aquel que pasa por el camino?

Rodonio. Aquel es Macrobio, mi padre, que va a su heredad.

ANTONIO. Por cierto, yo juzgara que era algún mancebo, según la disposición que lleva.

Rodonio. Pues a fe que ha más de noventa años.

VERONIO. Cuán pocos y raros son los hombres que viven todo el curso de la vida y llegan a morir la muerte natural, que se pasa sin dolor y viene por acabarse el húmido radical, y vemos a esotros animales comúnmente que viven el curso de su vida hasta la muerte natural y sin enfermedades, o muy raras.

RODONIO. Por cierto es de considerar si desto hubiera alguna lumbre en el mundo, que el hombre supiera las causas naturales por que enferma o muere temprano, muerte violenta, y por qué la natural fuera una gran cosa. Y si desto alcanzáis algo, señor Antonio, muchas veces os he rogado que antes que nos muramos mejoremos este mundo, dejando en él escrita alguna filosofía que aproveche a los mortales, pues hemos vivido en él y nos ha dado hospedaje, y no nacimos para nosotros solos, sino para nuestro Rey y señor, para los amigos, y patria, y para todo el mundo.

VERONIO. Si vos pedís esto, señor Rodonio, yo pido otra cosa, y es que me declaréis aquel dicho escrito con letras de oro en el templo de Apolo: Nosce te ipsum, conócete a ti mismo, pues los antiguos no dieron dotrina para ello, sino sólo el preceto, y es cosa que tanto monta conocerse el hombre y saber en qué difiere de los brutos animales. Porque yo veo en mí que no me entiendo, ni me conozco a mí mismo, ni a las cosas de mi naturaleza. $Y$ también deseo saber cómo viviré felice en este mundo.

ANTONIO. Dijo Galeno: ninguna evidente razón hay que nos muestre por qué viene la muerte. Hipócrates dijo: yo alabaría al médico que yerra poco, porque perfeta y acabada certinidad de la medicina no se alcanza. Y Plinio dijo: no sabe el hombre por qué vive ni por qué muere. También dijo, señor Veronio, el divino Platón, de vuestra pregunta, estas palabras: cosa muy ardua y dificilísima es conocerse el hombre a sí mismo; y dijo que el conocimiento de sí mismo no consiste en otra cosa, sino en conocer el ánima divina y eterna, y no pasó de allí. ¿Y queréis que en cosas tan altas y no alcanzadas de grandes varones os responda y dé satisfacción un pastor?

\section{Título II. Que los afectos de la sensitiva obran en algunos animales.}

VERONIO. ¡Oh santo Dios!, y que seguida y acosada viene aquella perdiz del Azor, y en verdad que se abate a valerse de nosotros, como es cosa natural que todos los animales se acorren al hombre en sus necesidades.

ANTONIO. Mas antes, señor Veronio, cayó muerta, veisla aquí.

VERONIO. Por mi vida así es, muerta está. 
ANTONIO. ¡Oh cuán eficaces son los afectos y pasiones del espíritu sensitivo para matar! Este caso responde a vuestra pregunta y nos da materia fecunda, y bastante, para este rato de conversación.

RODONIO. ¿No es cosa de notar, que venía volando esta perdiz, sana, y fue bastante el temor y congoja a quitarle la vida en un momento?

ANTONIO. ¿Desto os espantáis señor Rodonio? pues quiero os contar de otros animales, para que veáis cuánto obran los afectos de la sensitiva para vivir o morir. Plinio dice que un pescado longosta teme tanto al pulpo, que en viéndose cerca dél, se muere, y pierde del todo la vida. Y que si el congrio ve cerca de sí la longosta, hace lo mismo. Y cuenta el mismo Plinio del delfín que es muy amigo de la conversación del hombre, y que uno dellos tomó amistad y conversación con un niño que vivía cerca de un lugar marítimo, de manera que muchas veces llegaba el niño a la ribera del mar, y lo llamaba por este nombre, Simón, y el delfín luego venía, y el niño le daba pedazos de pan y otras muchas cosas. El delfín se ponía de manera que el niño subía encima, y lo llevaba y paseaba por la mar y lo volvía a tierra. Continuando pues esta conversación y amistad diole una enfermedad al niño, de que murió. El delfín, viniendo un día y otro al puesto donde ejercitaba su amistad, como no acudía el niño (siempre lo veían en aquel lugar), gimiendo en semejanza de lloro hasta tanto que allí mismo lo hallaron muerto. Cuenta también Eliano de otro delfín, que teniendo la misma conversación con otro mozuelo, lo paseaba cada día por el mar, y una vez, al subir, se descuidó el delfín de bajar las espinas del lomo, de manera que el mozuelo se hincó una espina por la ingle, y andando por el mar se desangró y cayó muerto. De lo cual el delfín tomó tanto pesar, que vino corriendo y se arrojó fuera del agua en tierra, donde se dejó morir. Pareceos, señor Rodonio, que obran estos afectos en los animales por el instinto y memoria sensitiva que tienen. Cuenta también Plinio que en el tiempo que Roma florecía se ayudaban los romanos en la guerra de los elefantes, y llevaban capitanía dellos por sí. Los cuales por su gran instinto, dice el mismo Plinio que entendían el pregón en la lengua romana. Y llegando un día el ejército romano a un gran río que tenía el vado dificultoso, mandaron pasar los elefantes delante, y el elefante capitán, que se nombraba Áyax, no osando pasar, estuvo detenido el ejército romano gran pieza, en tanto que fue menester pregonar que el elefante que primero pasase el río, le harían capitán. $Y$ entonces un elefante que se llamaba Patroclo osó pasar, y pasó el río, y todos los de más elefantes tras él y el ejército romano. Y, llegados a la otra parte del río, luego Antíoco cumplió lo que había hecho pregonar, quitando al Áyax las insignias que llevaba de capitán, a manera de jaeces y ornamentos dorados, y las mandó poner al Patroclo, por lo cual el Áyax nunca más comió bocado, y a tercero día lo hallaron muerto. También cuenta Plinio del perro y del caballo casos notables, que muertos sus amos sin más querer comer bocado murieron.

VERONIO. Bien creo que esto pasa en muchos animales y acontece cada día, aunque no se hecha de ver y es cosa notable, pero deseo mucho saber si acontece esto mismo a los hombres.

ANTONIO. Jesús, señor, mucho más sin comparación, porque tiene las tres partes del ánima: la sensitiva con los animales, la vegetativa con las plantas, la intelectiva con los Ángeles, para sentir y entender los males y daños que le vienen de parte de los afectos del alma, que son los mayores, y los de la sensitiva y vegetativa. Yo os contaré algunos ejemplos de hombres que murieron por el afecto del enojo y pesar, que es el que hace mayor daño, y después procederemos por los demás afectos.

Título III. Del enojo y pesar. Declara que este afecto del alma, enojo y pesar, es el principal enemigo de la naturaleza humana; y este acarrea las muertes y enfermedades a los hombres.

Rodonio. Pues estamos en esta materia, declárame primero de raíz por qué le acontece esto más al hombre de morir por estos afectos y pasiones del alma. Y también por qué tiene tantas diferencias de enfermedades que esotros animales no tienen, para que vengamos al conocimiento de las causas por que muere el hombre o enferma. 
ANTONIO. Como el hombre tiene el ánima racional (que los animales no tienen) della resultan las potencias: reminiscencia, memoria, entendimiento, razón y voluntad, situadas en la cabeza, miembro divino, que llamó Platón silla y morada del ánima racional. Y por el entendimiento entiende y siente los males y daños presentes, y por la memoria se acuerda de los daños y males pasados, y por la razón y prudencia teme y espera los daños y males futuros. $Y$ por la voluntad aborrece estos tres géneros de males: presentes, pasados y futuros. $Y$ ama y desea; teme y aborrece; tiene esperanza y desesperanza; gozo y placer; enojo y pesar; temor, cuidado y congoja. De manera que sólo el hombre tiene dolor entendido, espiritual de lo presente, pesar de lo pasado, temor, congoja y cuidado de lo por venir. Por todo lo cual les vienen tantos géneros de enfermedades y tantas muertes repentinas, cuando el enojo o pesar es grande, que es bastante en un momento a matarlos. Y cuando es menor, los pone gafos y los mata en pocos días o más a la larga (según la fuerza del enojo), y si es menor, que no mata, deja por las mismas causas humor para enfermedad en el cuerpo, y así son causa de las enfermedades. Las causas y el por qué y cómo esto pasa en el hombre, yo lo diré adelante, porque ahora no nos divertamos desta materia de ver cuanto obran los afectos en el hombre, así para muertes presentáneas como para otras muertes de allí a algunos días, y enfermedades.

RoDONIO. Pues contadme, por vuestra vida, que holgaré mucho de oír estas muertes.

ANTONIO. En Roma, estando el gran Pompeyo en unos comicios, acaso le cayeron unas gotas de sangre de un hombre herido en la ropa, y luego mandó a un paje llevarla y traer otra. Llegó el paje a dar la ropa a Julia, su mujer, y antes que dijese a qué venía, así como vido Julia las gotas de sangre en la ropa de su marido, luego se cayó amortecida y mal parió, y murió.

RoDONIO. Por cierto ella fue muy apresurada, que aun no quiso esperar a oír el mensaje y entendiera que la sangre no era de su marido.

ANTONIO. Ahí veréis vos, señor Rodonio, cuanto obra en los mortales el afecto del amor cuando se pierde lo que se ama, pues sola la imaginación falsa y sombra del mal, que fue la sospecha de lo que podía ser, sin estar cierta la mató en un momento.

Rodonio. Pasa adelante en estos cuentos, señor Antonio, por hacernos merced, que nos deleitan y alegran en extremo, pues el lugar y el tiempo nos convidan a ello y me parece que montará mucho verlos para que yo (escarmentado en cabeza ajena) me sepa guardar y no me acaezca otro tanto, entendiendo bien la fuerza y operación destos afectos.

ANTONIO. En el tiempo del Rey don Alonso onceno, siendo gobernadores del reino dos Infantes, don Pedro y don Juan, tíos del Rey don Pedro, que era niño, habiendo hecho muchas guerras y batallas en la tierra de Granada como esforzados y valientes caballeros, volviéndose para tierra de cristianos venía don Pedro en la vanguardia, y don Juan en la retaguardia cargó gran multitud de moros, que venían haciendo tan grande daño en la retaguardia, que tuvo necesidad de enviar a decir a don Pedro que se detuviese y le viniese a socorrer. Lo cual, queriendo él hacer con grande ánimo y voluntad, halló su gente tan acobardada, que no quería volver contra los moros ni pudo hacerles por ninguna vía volver a socorrer a su tío y amigo. Tomó desto tanto enojo y pesar, que sacó la espada para herirlos y sin poderla menear perdió luego la habla y sentido, y cayó muerto del caballo sin más se menear ni quejarse, no otra señal de vivo. Algunos de los suyos viendo esto, volvieron a dar noticia dello al Infante don Juan, y sabido por él tan doloroso y triste caso, tomó tanto enojo y pesar, que luego perdió el sentido y habla, y se puso gafo y tullido de todos sus miembros, que no pudo menearse y luego a la tarde murió.

RoDonio. Por cierto, señor, extraño caso fue en caballeros tan animosos y magnánimos.

ANTONIO. Pues sabed que en tiempo del cristianísimo Emperador don Carlos $\mathrm{V}$, en las guerras de Hungría, en el cerco de Buda, era capitán Raisciao Suevo, el cual, como cuenta Paulo Jovio, tenía un 
hijo, valiente mancebo, el cual, sin dar parte a su padre, hizo un desafío y vinieron a batalla a vista de los campos. Estando los grandes del ejército con el capitán mirando la batalla de los dos, hacíalo maravillosamente él de su parte, que no sabían quien era, y alabábanlo. Pero al fin fue vencido, y muerto. Queriendo saber el capitán y los demás quien era tan buen caballero, fueron allá y lo mandaron desarmar, y en quitándole la visera, y en conociendo el capitán por la cara, y cierta joya que traía al cuello, que aquel era su hijo, en el mismo instante cayó muerto y lo enterraron con su hijo, y claro está que no era pusilánimo pues buen cargo tenía. Ginebra, mujer de Juan Ventivolo, murió de repentino dolor, que le dijeron de súbito que sus hijos habían sido vencidos en una batalla. Son tantos y tan innúmeros los ejemplos que en esto se podrían traer, que era hacer un gran volumen y estorbar nuestro propósito y materia, y por evitar prolijidad los dejo. Mariana porque vido su hijo caer en un charco, en zabulléndose en el agua que lo perdió de vista, se cayó muerta, y a poco rato el hijo sano y bueno lloraba la madre muerta. En nuestros tiempos hemos visto a muchos, por sólo caer en desgracia del Rey, nuestro señor, o por oír de su boca algunas palabras retándoles lo mal hecho, irse a su casa y echarse en la cama y a pocos días morir, como tendrán buena experiencia los que en ello han mirado, que son muchos y de notar, a los cuales no es razón que los nombremos aquí. Y murieron también de pesar de perder el favor de Rey, como cosa de gran pérdida, y que ellos tanto amaban y estimaban, y con razón se debe estimar. De manera que, una gran pérdida (como causa y fuente de pesar y enojo), luego tiene de mano la muerte en perdiendo la esperanza de remedio. En nuestros días también vimos al Arzobispo de Toledo, fray Bartolomé de Miranda, preso y despojado de su silla y llevado a Roma, y en mucho tiempo que su pleito se trató, vivía con la esperanza mientras estuvo en duda el fin. Pero cuando llegó la sentencia difinitiva del Papa, luego se echó en una cama, y a muy poquitos días murió. Porque entretanto que está en duda el daño o pérdida, no obra este afecto del todo su potencia. Por lo cual usa de este aviso, que será gran caridad y buena obra meritoria: cuando se ha de dar una mala nueva, disminuirla y ponerla en duda. Y más con las preñadas, enfermos y viejos. Y aun cuando sea de gran placer, no se ha de decir de golpe, sino poco a poco y poniéndola en duda, porque también el gran placer repentino mata, como adelante se dirá.

Rodonio. ¡Oh alto Dios, y de cuánta eficacia son estos afectos en los hombres! Desta manera, señor, paréceme que es mejor no tener grandes cosas ni riquezas donde pueda haber grandes pérdidas, para evitar estos peligros.

ANTONIO. Sí, como adelante diremos, y aun también en pequeñas pérdidas y daños acontece esto cada día. ¿Quien podrá contar las muertes que de pequeños daños y pequeños pesares han venido? uno porque se le murió el ganado; otro porque se hundió la mercaduría; el otro porque le hurtaron los dineros; el otro porque jugó y perdió; la otra porque perdió a su marido; la otra porque vido llevar a su hijo preso por deuda de seis reales se cayó muerta, como pocos días ha vimos a Ludovico; el otro porque le engañaron; el otro por una fianza; el otro por enojo de palabras, no pudiéndose vengar; el otro porque le echaron en la cárcel; el otro porque le condenaron en la sentencia o le ejecutaron; el otro porque fue vencido en la batalla; el otro porque hizo mala venta; el otro por su necedad erró el negocio; el otro porquese le fue el hijo o hizo algún desatino; el otro porque fue afrentado; la otra por el descontento que se juzga mal casada; la otra por una mala nueva; el otro porque perdió el favor. $Y$ por otras muchas causas menores y de poco momento, como el Rey que murió por enojo de cinco higos; el otro por un vaso; el otro por no acertar la enigma de los pescadores, todos se echaron en la cama. Y por el pesar, que es la discordia entre alma y cuerpo que llamó Platón, cesa la vegetativa y hace deflujo, y les da una calentura, y pónenle nombre de enfermedad según a do va, y mueren en algunos días, a la larga otros se vuelven locos. Son tantos los que he visto después que esto entiendo, que si hubiera de contarlos por menudo, primero nos anochecería. Porque he visto morir desta manera gran número, como podréis mirar en ello de aquí adelante. Este afecto de enojo y 
pesar obra más en las mujeres, y más en las preñadas, y así mueren infinitas de pequeños enojos y pesares, que les basta poco, pues sólo el olor del candil o pavesa cuando se apaga es bastante para que la mujer malpara, como dice Plinio. Cuanto más una cosa que tanto obra y de tanta eficacia, como es el pesar y enojo, hace de tener gran recato con ellas y aun ponerse ley. Finalmente, le acontece al hombre lo mismo que cuando niño, y guarda aquella misma propiedad y naturaleza. Porque si a un niño que tiene una haldada de higos, le quitan uno por fuerza, luego los arroja todos, y llorando y echando lágrimas se echa a estragar. Así hace lo mismo después de hombre, por una pequeña pérdida contra su voluntad arroja todos los demás bienes que tenía, y los pierde, y se echa sepultura, o le causa una enfermedad aquel pesar y enojo, el cual si por entonces no mata, deja a su hija la tristeza de aquel daño en la persona, para que más a la larga y en más tiempo, la mate. Finalmente os digo, señor Rodonio, que de cien hombres que mueren, o cien mujeres, mueren los ochenta de enojo y pesar. $Y$ los niños que mueren cuando les dan sus madres leche, también es de pequeños enojos y pesares de las madres. Finalmente, enojo y pesar no habrían de tener este nombre sino la mala bestia del género humano, o pernicioso enemigo suyo, o el hacha y armas de la muerte.

\section{Título IIII. Del enojo falso. Avisa que el enojo falso o imaginado, también mata como el verdadero.}

Conózcase el hombre en esto, que no solamente el enojo y pesar cuando es cierto y verdadero lo mata, pero aun también cuando es falso y fingido con sola la sospecha, como a Julia y a Mariana y otras muchas mujeres y hombres.

Egeo, Rey de Atenas, enviando a su hijo Teseo a Creta a la aventura del Minotauro, le mandó que si volvía vitorioso pusiese en las naos velas blancas. El cual, con el gran placer de la Vitoria, olvidó el mandato de mudar las velas a la venida, y subiéndose el padre a un risco que caía sobre el mar para ver si venía vitorioso y viendo que no traía velas blancas, tomó tanto pesar que desde allí se arrojo en el mar y murió.

Píramo y Tisbe, no pudiendo gozar de sus amores en casa de los padres, concertaron que a tal hora estuvieren en cierta fuente y lugar apartado de la ciudad, donde vino la Tisbe primero y hallado una leona en aquel lugar, perturbada toda, huyendo a una cueva se le cayó la toca. La cual tomó la leona, y llegando Píramo y viendo la toca de su muy querida y amada Tisbe en poder de la leona, con la sospecha falsa, y aun necia, que la leona habría comido a su enamorada, tomó tanto pesar de su tardanza, que luego se mató con su espada. Los cuales, todos, en muy poquito tiempo que aguardaran excusaran sus muertes.

RODONIO. Por cierto, señor, grandes cosas nos habéis dicho y dignas que se escriban para que se mejore el mundo, y los hombres sepan y entiendan por qué mueren, y sabiéndolo, sepan guardarse de tan mal peligro, que suelen decir, menos hieren los dardos que primero se ven venir. $Y$ ahora, de nuevo os torno a rogar que me digáis si habrá remedios para obviar y resistir a esta mala bestia, que no haga este daño, y el género humano se defienda della.

\section{Título V. De los remedios notables contra enojo y pesar.}

ANTONIO. Buenos remedios hay para los que tuvieron buenos entendimientos.

El primer remedio consiste en saber y entender todo lo dicho y las grandes fuerzas que tiene este enemigo del género humano, como por lo dicho se entenderán. $Y$ así, conociendo al enemigo y sabiendo sus fuerzas y malas obras, el hombre no se descuidará ni le dará entrada, porque la piedra que se ve venir no hiere, como vos dijistes, porque le hurta el cuerpo, y si no la ve, lo hiere, como los 
que saben donde está el peligro en la mar, con prudencia se apartan y libran dél, y los que no lo saben simplemente caen en él, como el mozuelo simple que no conociendo ni sabiendo nada de la ballesta de lobos, tocó a la cuerda, y vino la saeta enherbolada y lo mató como a bestia, porque no supo del peligro como hombre. Así el hombre y la mujer, con sólo el saber y conocer esta bestia (por lo que está dicho) se librará della, y en tocando a su puerta sabrá a qué viene, y no le dará entrada, y se defenderá della.

El segundo remedio consiste en palabras de buen entendimiento y razones del alma. Y decir: ya te conozco mala bestia, y tus obras y daños; no me quiero dar en despojo a ti, como los simples que no te conocían antes, más quiero sufrir este pequeño daño que pudiera ser mayor que no perderlo todo, y mi vida con ello, y añadir otro mal mayor encima, como perder la salud o la vida, que monta más, y por esto no se me quitará esta pérdida o daño, antes añadiré mal a mal. A lo pasado y hecho no hay potencia que lo pueda deshacer, pues ha de ser hecho, sea hecho. Inestable es la fortuna que siempre se muda, pues quiero guardarme para otro tiempo, que éste se acabará. Dijo un sabio: haz de grado y placer lo que por fuerza has de hacer. Y decir: las armas de la fortuna adversa son la tristeza, si con este infortunio no me entristezco venzo a la fortuna y a sus fuerzas vuelvo vanas, botas y sin efeto contra mí. Si el catedrático de Salamanca supiera este aviso cuando le hurtaron quinientos ducados, y murió a tercero día a la hora del mediodía, y los dineros parecieron a la noche, viviera como sabio y no muriera como simple. $Y$ otros muchos. $Y$ la madre que por falta nueva de la muerte de su hijo, murió, y de allí a tres horas vino sano y bueno.

¿Cuántas cosas juzga el hombre a las veces por dañosas que después se convierten en bien y provecho? ¿Y cuántas juzga por útiles y buenas, y se convierten en malas y dañosas? Uno por estar encarcelado y condenado a muerte se convierte en Rey. Otro por salir herido de la batalla, en la herida halló la salud. Y otro se libró de una cuartana. Otro por perder el dinero en el camino, no perdió la vida cuando fue a dar en manos de salteadores. Otros condenados a muerte y echados a los leones, vinieron a ser reyes, no dándose en despojo luego, a este enemigo. Otros, alcanzando estados y riquezas muy deseadas y con gran trabajo, aquellas mismas fueron causa de sus males, infortunios y muertes. ¿Cuántos desearon ser Emperadores y reinar y lo alcanzaron y fue por su mal? ¿Y para casos desastrados y muertes infelices y violentas? Y el día dichoso en que aprehendieron el Imperio fue principio y causa de su desventurada suerte. Si en ejemplos nos hubiéramos de detener sería impedir nuestro intento. $Y$ decir: pues Dios ha sido servido de permitir que me viniese este daño, muerte o infortunio, quiero yo querer lo que Dios quiere. Dios lo dio, Dios lo quitó. Él sea loado, que él lo sabe remediar por vías que yo no entiendo. A los suyos envía Dios azotes en este mundo, y no les alega montón de castigo para el otro. Un sabio que todo le sucedía muy prósperamente, vivía muy triste por ello. Dijo Séneca, no hay hombre más infelice y desdichado, que el que no le viene adversidad ninguna, porque Dios no juzga bien de éste. Con la mucha lozanía y abundancia no granan las mieses. Las ramas muy cargadas de fruta se quiebran. La demasía fertilidad no llega a madurez. Después de lo dicho toma el librito Contemptus mundi, y donde se abriere, lee un capítulo. Rodonio. Por cierto, señor Antonio, con letras de oro merecían estar escritos estos remedios, y no había de haber hombre que no los sacase y los trujese consigo, como una nómina colgando al pecho, para librase del pernicioso enemigo del género humano y conservar su vida. Pero, hacedme placer, si hay algunos otros remedios me los digáis.

ANTONIO. Sí los hay, y consisten en palabras de un buen amigo o del médico, si le ha sucedido enfermedad por daño o por enojo, que la mejor medicina de todas está olvidada e inusitada en el mundo, que es palabras. Éstas serán conforme al caso acontecido, fuere de las dichas en el segundo remedio, como serán consolatorias y de buena esperanza, trayéndole a la memoria otros bienes que 
tiene, y a los que van delanteros en aquel género de trabajos y otros mayores infortunios, y la insinuación retórica.

\section{Título VI. De la ira y su remedio, la insinuación retórica.}

RODONIO. ¿Qué cosa es la insinuación retórica?

ANTONIO. Es una razón que quita el enojo como con la mano y digna de ser sabida, (cuando el daño fue por arbitrio de hombre, y hay esperanza de venganza, que entonces se dice ira), especial cuando es ira impetuosa por haber reñido con otro y desea venganza. Dícese insinuación, porque el que pone esta medicina se hace de la voluntad, seno y bando del agraviado que quiere curar, y dice: ¿qué ese agravio os hizo? ¿Estas palabras os dijo? de la paciencia que tenéis me espanto, yo no lo pudiera sufrir, tenéis la mayor razón del mundo y yo os ayudaré, matémoslo, destruyámoslo por esta vía y por ésta, hasta la muerte os ayudaré, que también me hizo a mi este agravio y éste. Cuando ya está metido en el seno del agraviado y ya le da crédito, entonces pone dilaciones en el negocio: ¿cómo señor? no hagáis cosa sin mi, mañana, o de aquí a tal hora, iremos a tomar venganza. $Y$ pasado aquel rato vuelve la hoja, y dice: ahora, señor, miremos los fines en que pueden parar estas nuestras iras, que quien no mira el fin no usa de razón de hombre. Puédese seguir este daño y éste, que será cuanto mayores que el que tenemos, más nos vale dar pasada a este pequeño daño que no buscar otro muy grande, que vivamos toda la vida en desasosiego y pérdida. Más es vencerse a sí mismo que vencer a los enemigos, y otras semejantes razones. $Y$ como ya le da crédito por ser de su voluntad y seno, luego a la hora lo toma y es persuadido. Yo he visto que esta insinuación retórica obra maravillosamente, y quita el enojo, y no pasa el daño adelante.

Rodonio. Conténtame tanto oíros, que no querría que acabásedes si hay otros algunos remedios, pues tanto importa este negocio, no los dejéis de decir.

ANTONIO. Sí hay, como es luego gargarizar con agua fría y con vinagre blanco aguado, comer el jugo de cosas agrias, y no beber vino ni comer hasta ser pasada la alteración. Tomar buen olor, la eutrapelia de un buen amigo (que es buena conversación) y con él salirse al campo, donde el movimiento de los árboles y el suave ruido del agua se oiga. La música también es eficacísimo remedio, que quita el daño que el enojo está haciendo, como los mordidos de las tarántulas sanan bailando a buena música, y no con otra cosa, y si falta la música muere luego.

RODonio. Ahora digo que tenía gran razón Ismenias, médico Tebano, que curaba todas las enfermedades con la música.

ANTONIO. Algún día tocaremos esto, cuando demos las causas de todos.

Estos remedios aprovechan, pero todavía más sacado el papel que trae por nómina colgado al pecho de las razones del segundo remedio, y leyéndolas. Y entienda el hombre, que la ira es una breve locura, y no se debe dar crédito, que de allí a un rato sentirá de otra manera.

\section{Título. VII. De la tristeza. Avisa los daños y muertes que acarrea la tristeza.}

La tristeza y descontento es una hija menor, que pare y produce el gran pesar, enojo o ira por alguna gran pérdida o daño pasado, y son las reliquias del gran flujo o decremento que violentamente causó aquella especie aborrecida, sacudiéndola y arrojándola de sí el ánima, no queriendo que fuera en el mundo, y con ella el jugo del celebro do se asentó (como adelante se declarará). Y como después se queda en casa la discordia entre alma y cuerpo, que pone aquella especie aborrecida y enemiga, siempre está desechándola y sacudiéndola, y con ella su jugo, poco a poco, y gota a gota, mucho menos que cuando llegó primero nuevamente, como el hisopo pasado ya su deflujo grande está goteando. Ésta hace el daño poco a poco, como la invidia, y de la misma manera los tristes se secan 
y consumen sin calentura, porque cesa su vegetación con esta tristeza y descontento, a la cual llamó Platón discordia de alma y cuerpo. Ésta hace la vida triste e infelice, como su contraria, la alegría, la hace felice y suave. Y así dijo Platón: la cosa más dulce es pasar toda la vida sin tristeza. A éstos suele venir la hética y enfermedades del cuero, como sarna, piojos, lepra, apostemas y otras malas nacidas. Los tristes duermen más que los alegres, porque en la vigilia, aquel lento deflujo dicho, les derriba y deseca más el jugo de su celebro que a los alegres.

Para remedio de la tristeza toma estos avisos. Cuando la esperanza de tu bien pereció, luego busca, inquiere y imagina otra. La cosa que siempre te pesa della, quítala delante los ojos o hazla ajena. También a éstos será grande alivio leer muchas veces el segundo remedio, que dijimos se ha de traer al cuello colgando como nómina. Aprovecha también saber y entender estos daños que la tristeza obra en la salud humana para defenderte della. $Y$ finalmente, desecharla, así por las razones del alma como por alegrías exteriores y corporales.

AVISO a las mujeres que muchas mueren por el descontento de juzgarse mal casadas. Este afecto de tristeza, causado por especie entendida y aborrecida, sólo el hombre lo tiene y le muda sus condiciones.

\section{Titulo. VIII. Del afecto del miedo y temor. Avisa los daños y muertes que acarrea el miedo.}

ANTONIO. Síguese ahora, el afecto del miedo y temor de lo que está por venir. Este afecto aunque mata, como es de daños que aún se están en duda y no están ciertos, no es tan vehemente su operación como del pasado, pero cuando ya se acercan y se ven ciertos también matan. Como murió el hijo a quién el padre, de industria. por escarmentarlo, dio orden que de burla y fingidamente lo condenasen a muerte, y cuando quiso deshacer la burla, no pudo, porque dejó llegar cerca el miedo y así murió. Otros muchos se ha hallado en las cárceles muertos, por estar condenados a muerte y llegarse el día y hora. Otros, llevándolos a la horca, antes que a ella lleguen mueren. Este afecto es de la sensitiva, y obra también en animales, como en esta perdiz cuando venía cerca el azor, y el pescado longosta cuando ve cerca al pulpo, como dijimos. Éste obra mucho en las mujeres, y más en las preñadas, que de muy pequeños miedos repentinos o aglayos malparen y mueren, y aunque sean falsos, con sola la imaginación, el miedo las mata. ¿Cuántas murieron por imprudencias de jueces, por escándalo de riñas y espadas desenvainadas? Cecilia por una pantasma hecha por manos de unos mancebos para burla, se amorteció, y nunca más torno a la vida. Son tantas, y acontecen tan continuamente, como todos lo saben y ven cada día, que no es menester traer ejemplos, pues de sólo ver un niño que va a caer, o decir que viene el toro, o torcerse el chapín, les viene gran daño, y algunas veces se han visto malparir. Finalmente, más daño hace el temor que no la cosa temida cuando llega. $Y$ cuando este afecto no mata, también derriba su parte de humor, y lo hace vicioso para adelante, y el humor que engendra es melancolía. La cual hace gran daño a los mortales, aunque no los mate sino a la larga. Pone tristezas en el celebro y corazón, hace enojarse mucho, de lo cual vienen daños: pone mala condición, trae falsas imaginaciones y sospechas, pone miedos, y conjugas falsas, y malos ensueños, pone cuidados que dan fatiga sin ser menester. Es bueno y aprovecha saberle estas condiciones y naturaleza, para no darse crédito el hombre o mujer que la tuviere, porque es mentirosa y falsa, en tanto que algunas parecen endemoniadas y no lo son. Y esta melancolía acarrea desesperación. Tiene remedios que son: el primero, como está dicho, conocerse la condición y naturaleza para no darle crédito. El segundo es alegría, buen olor, música, el campo, el sonido de árboles y agua, buena conversación, tomar placeres y contentos por todas vías. 
RoDONIO. ¿Habrá algún remedio, señor Antonio, para defenderse deste segundo afecto, miedo y temor?

ANTONIO. No siento remedio bastante mas destos que diré. El primero es saber estos daños que obra en los hombres y conocellos para no dejarse matar dél, sabiendo el peligro donde está. El segundo remedio es usar de prevención, y decir: ¿si este miedo o éste me viniese, habría yo de ser tan pusilánimo que me dejase matar dél? Y la mujer lo mismo, diciendo: ¿si este miedo me viniese, o viese yo la pantasma fingida y mentirosa hecha por mano de hombres que la otra vido, y dello malparió y murió, había yo de ser tan necia como ella, y por un miedo falso y mentiroso perder la vida? Usando desta prevención, que también aprovecha para el pasado, cierto se defenderán dél, porque, como dijimos, menos hieren las piedras que se ven venir. $Y$ en cualquier esperanza dudosa de gran aventura, sentencia o nueva esperada, usar de las razones del alma: lo que es, ya es, o lo que ha de ser no lo puedo yo deshacer, de balde me fatigo y añado mal, y usando prevención, esperar siempre lo peor.

Este afecto derriba con vehemencia del celebro un humor líquido, y así luego se zullan los animales, y aun el hombre también. En Peonia, cuenta Plinio de un animal por nombre Bonasus, semejante al toro, tuertos los cuernos que no le sirven, para pelea ayudase de los pies y huida, que con el miedo cuando le siguen se zulla tanto, que le dura tierra de tres obradas, y es tan grave el hedor, que abrasa como un fuego a los que le siguen. A las raposas también les acontece lo mismo.

Este afecto también derriba aquel humor líquido, claro y transparente, por el cuero, y así mudan el color muchos animales con el miedo, como el pulpo y el animal tarando, porque aquel humor transparente como el vidrio, parece del color sobre que está situado.

RODONIO. Gran remedio cierto es el que habéis dado para entender y conocer al enemigo, y saber do está el peligro para guardarse dél, y antes que venga, usar de la prevención dicha, que es el segundo remedio. Ahora, señor, por vuestra vida, pasa adelante en esta materia.

\section{Título IX. Del afecto de amor y deseo. Avisa que este afecto mata y hace diversas operaciones.}

ANTONIO. Síguese ahora el afecto del amor y deseo. El amor ciega, convierte al amante en la cosa amada, lo feo hace hermoso, y lo falto perfeto, todo lo allana y pone igual, lo dificultoso hace fácil, alivia todo trabajo, da salud cuando lo amado se goza. También mata en dos maneras, o perdiendo lo que se ama, o no pudiendo alcanzar lo que se ama y desea. En la primera manera, es tan común, que se ve cada día en la mujer que bien amaba a su marido que perdió a pocos días morir, que contar las que hemos visto sería ocupar papel. Aquí vimos morir en una semana dos hombres, y en la misma semana enterrar sus dos mujeres. Deyanira, mujer de Hércules, oída la muerte de su marido luego expiró. Otras muchas se mataron en la gentilidad.

\section{$[\ldots]$}

Título XXIII. Afecto del placer, contento y alegría, que es una de las tres columnas que sustentan la vida humana.

El placer, contento y alegría son la principal causa por que vive el hombre y tiene salud. Y el pesar y descontento por que muere. A este contento y alegría, llamó Platón concordia del alma y cuerpo, en la cual puso la salud, y al pesar y descontento llamó discordia del alma y cuerpo, y en este puso las enfermedades, y con mucha razón, aunque los médicos no lo entendieron.

RODonio. Todo lo que habéis dicho va contra lo que tienen todos y el vulgo, que piensa que las muertes suceden de las comidas cuando no son naturales, por vejez, y que la vida consiste en 
buenas comidas, y que del comer se engendran los malos humores y vienen las muertes. Y así dijo Arnaldo: mucho más mata la gula que la espada.

ANTONIO. Engáñanse mucho. Verdad es que la comida de mala calidad, o de algún veneno, o demasiada, que el calor no la puede abrazar, engendra mal humor vicioso, y desbarata la armonía del estómago, como los afectos desbaratan la armonía principal del celebro, como adelante se declarará. Y mucho más daño causan las cenas porque cae una comida sobre otra, sin dormir, y la orden de naturaleza y buena salud es de cada comida tomar el jugo de tres maneras, y enviar su parte a este rey y príncipe, que se dice miembro principal o raíz, el celebro, o médula de los sesos, y esta parte le envía sus criados del estómago en el sueño principalmente, que es una manera, como se ve en los niños, que tras cada comida duermen. Por esto las grandes cenas son causa de malos humores y enfermedades, también por otra razón que adelante se dirá. Aristóteles siendo preguntado que había visto en Sicilia respondió: vi un monstruo que se hartaba dos veces al día, porque vido a Dionisio, Rey de Sicilia, comer dos veces hasta hartar. Pero es meaja el daño que el comer demasiado hace en los hombres en la armonía segunda del estómago en comparación con del daño que hace el enojo y pesar (porque éste yerma el mundo como dicho es), y otros afectos en la armonía primera y principal del celebro, donde habita y mora el ánima divina, desbaratándola y haciendo discordia entre alma y cuerpo, mediante las especies contrarias y aborrecidas que ahí entran por las cinco puertas de los cinco sentidos.

Rodonio. Desta manera, señor Antonio, ¿mejor es tener poco que comer que mucho? pues comúnmente vemos a los pobres vivir más tiempo y más sanos que los ricos.

ANTONIO. ¡Y cómo si es mejor!, sin comparación, porque el hombre se escapa deste daño del mucho comer y del otro mayor, que dijimos, enojo y pesar, porque no tiene de donde le vengan grandes pérdidas ni grandes enojos. Pero dejemos esto ahora para adelante, y vengamos a dar las causas de todo lo dicho, que yo lo pondré claro lo más que pudiere.

Habéis de saber que, ordinariamente, la mayor parte del humor que en el cuerpo humano se cría, cae del celebro o médula de la cabeza, y a esta caída llaman catarro o reuma, cuando cae de la parte anterior de la cabeza. $Y$ sabed que las demás enfermedades que tienen infinitos nombres, es humor también que cae de la cabeza por la parte posterior, como más largamente se declarará en el diálogo de la vera medicina. Y si la caída, o catarro, o reuma de ambas partes es grande, y de gran causa, y vehemente, una sola caída (catarro o decremento del celebro, que todo es uno) es bastante para matar, como se vido en el gran catarro pasado, del cual tan infinito número de gentes murió, que fue una fina pestilencia. Y estos catarros, caídas o decrementos del jugo del celebro pasan en el hombre de esta manera. Primero cae la ventosidad, secundariamente lo más acuoso y flujible, que es la cólera, y lo tercero lo viscoso, que es la flema, la cual como se ve cada día en una cabeza de carnero, y se puede ver en las de los hombres, después de muerto queda colgando un pedazo de flema, como gargajo de la médula de los sesos. Yo tengo opinión que este humor viscoso (que es la flema y lo postrero que cae) es lo que mata a los hombres, y hace los mayores daños. Pero sea el que fuere, si este humor cae al pecho, da la tos; y si cae al corazón, da epilepsia; y si va al pleuresi, da mal de costado; y si va al bazo da melancolía; y si va al hígado, desbarátale su calor nativo, y viene calentura; y si va a los riñones, da mal de riñones; y si va a los pies, la gota, etc., como más largamente se tratará en el diálogo de la vera medicina. Y aunque los médicos antiguos juzgaron de otra manera (porque no alcanzaron las caídas, catarros y decrementos del jugo del celebro por la parte posterior y nuca, o vicaría del celebro, que es la médula espinal, que nace del celebro), su dicho no forzó a la naturaleza a que fuese aquello que dijeron, antes ella se quedó, y está en lo que fue y es, y su dicho no la mudó, antes sus dichos se mudarán, pero esto quédese para su lugar. Yo tengo muy visto y experimentado que esto pasa así en el hombre, que cuando con esta humidad, jugo, 
chilo, o substancia, la raíz, que es el celebro y la pía mater, está firme haciendo su oficio oculto (que es tomar y dar) el cual se dirá adelante, entonces es la salud. Cuando cae de allí y se disminuye y descrece el celebro, y cesa su oficio de raíz, que es (como dijimos) tomar y dar, son las enfermedades. $Y$ sabed que este celebro es la raíz principal que vegeta el cuerpo del hombre, que se dijo árbol del revés. Y el aumento desta es la salud, y la disminución son las enfermedades.

Tres columnas o empentas tiene este jugo de esta raíz principal, y la pía madre, para estar firme en su lugar y hacer su oficio, donde da la salud, que son éstas: la primera, alegría, contento y placer. La segunda, esperanza de bien. La tercera, buen calor del estómago, y concierto de la armonía segunda del estómago, como arriba dijimos. Y tiene muchos enemigos y contrarios que le hacen caer aquel jugo del celebro y armonía primera, cada uno en su proporción, según su fuerza y eficacia con que mueven y sacuden la pía madre, y estorban su vegetación que brota para arriba hacia el cuero, como más largo se declarará en los diálogos. Pero el mayor que tiene es enojo y pesar, el cual, si es grande, de una sola caída o deflujo sufoca y apaga el calor nativo del corazón y estómago, y en un momento mata, como está dicho, porque derriba en un instante tanta cantidad del jugo del celebro, contrario al estómago por su frialdad, que basta a sufocar el calor del corazón y enfriar el calor del estómago, y en un momento mata, y la causa y como esto se hace es ésta.

\section{Título. XXIIII. La manera como hace este daño el ánima en los afectos.}

Como allí en el celebro está el ánima divina, entendimiento, razón y voluntad, y potencias del alma, llega aquella especie que entra por uno de los cinco sentidos, tan aborrecida y contraria, y que tanto le duele al alma, que luego el entendimiento y voluntad la arrojan y sacuden con movimiento de la pía madre de sí. No queriendo que aquello fuera en el mundo, arrójanla con tal violencia, que arrojan también con ella toda la sustancia, humidad y jugo que tenía la raíz, el celebro, para su alimento, salud y vegetación de sus ramas, y para hacer su oficio la pía mater (el cual se dirá más largamente). Deséchanla y arrójanla como cuando a un animal le dan una cuchillada en el pie y da muchas coces, a menudo arrojando y desechando aquel dolor, y arrojara también el pie, si fuera la materia blanda y pudiera desasirse, como acá puede el jugo y humidad del celebro. Esto hace el ánima con el movimiento de la pía madre, que es la mano del ánima.

Al orador que, subiendo a la cátedra a orar (en Roma), se le olvidó totalmente la oración que iba a decir, y el que en la enfermedad olvidó su nombre propio y el de sus esclavos, y el que olvidó las letras, y el que viniendo camino un aire frío que le daba en el colodrillo le hizo perder la memoria, fue que se les cayó y corrió la humidad del celebro, y con ella todas aquellas especies que en ella estaban situadas.

\section{Formato de citación}

Sabuco, Oliva (1587/2006). Nueva filosofía de la naturaleza del hombre. Athenea Digital, 10, 263-275. Disponible en http://antalya.uab.es/athenea/num10/sabuco.pdf. 